Escuela de Ciencias Sociales y Humanidades, UNED, C.R. URL: http://investiga.uned.ac.cr/revistas/index.php/espiga/index ISSN: 1409-4002 • e-ISSN: 2215-454X http://dx.doi.org/10.22458/re.v17i34.1791

\title{
Violencia, trata de personas y extinción social. Apostillas sobre su contexto y devenir histórico social
}

\author{
José Manuel Grima* \\ (iD) https://orcid.org/0000-0002-9103-7110
}

Recibido: 24 de mayo, 2017 - Aceptado: 27 de setiembre, 2017

\section{RESUMEN}

La trata de personas asumió diversas formas a lo largo de la historia. Aquí se trata de comprender el escenario actual (capital en estadio neoliberal), al señalar los cambios operados en el mismo respecto del estadio precedente. Se propone un recorrido por tres apostillas, a modo de ensayo, sobre el margen del problema en cuestión. Un primer sendero sobre las interrogantes que postula la teoría de la colonialidad, en la reproducción de patrones de poder. La segunda parada apuesta a describir brevemente el rol del Estado-nación en el estadio neoliberal del capital, para cerrar con un análisis del pasaje hacia sociedades, cuyos dispositivos de gubernamentalidad producen exclusión-extinción social, y se entiende la trata de personas como uno de estos.

Palabras clave: trata de personas, colonialidad, capital en estadio neoliberal, Estado, genocidio neoliberal, exclusión-extinción social.

\section{Formato de citación según APA}

Grima, J. M. (2017). Violencia, trata de personas y extinción social. Apostillas sobre su contexto y devenir histórico social. Revista Espiga. 16(34), 169-182. Doi: http:// dx.doi.org/10.22458/re.v17i34.1791

\section{Formato de citación según Chicago-Deusto}

Grima, José Manuel. «Violencia, trata de personas y extinción social. Apostillas sobre su contexto y devenir histórico social». Revista Espiga, 16, n. ${ }^{\circ} 34$ (julio-diciembre, 2017): 169-182. Doi: http://dx.doi.org/10.22458/re.v17i34.1791

* Licenciado en Sociología. Docente e investigador. Asesor sobre Promoción y Protección de Derechos de Niños, Niñas y Adolescentes (NNyA) de la Secretaría de Derechos Humanos y Pluralismo Cultural de Argentina. Universidad de Buenos Aires. Argentina. jgrima@jus.gov.ar 


\section{Introducción}

La producción académica sobre el fenómeno de la trata de personas ha tenido un doble sesgo teórico a lo largo del tiempo. Por un lado, se lo ha abordado en su carácter de delito desde las ciencias jurídicas, las que se explayaron esencialmente sobre el acceso a la justicia; y por otro lado, en su faz de grave violación a los derechos humanos de aquellas personas tomadas por el fenómeno, existiendo una predilección por reflexionar sobre su restitución. Pero ambas miradas han carecido de análisis centrados en la trata de personas como consecuencia de procesos de producción sistémicos que emergen en determinados contextos socio históricos; en este ensayo se aborda el ámbito latinoamericano actual.

En estas breves reflexiones, a modo de ensayo, se apuesta a compartir algunos interrogantes en esa dirección. Estas solo pretenden ser la puesta en diálogo de tres elementos que pueden ayudar a interpretar el contexto en el que se produce la trata de personas con fines de explotación. La colonialidad como construcción histórica que ha modelado las sociedades latinoamericanas, el rol de los Estados-Nación en el continente en un estadio del capital de carácter neoliberal y finalmente la redefinición del concepto de genocidio bajo el imperio del mercado, es decir de una gubernamentalidad cuyos dispositivos son operados por este y se orientan a la exclusión-extinción social.

\section{Primera apostilla. Colonialidad}

Cuando llegamos a Quillabamba había una señora grande y gorda que se nos acercó y nos preguntó si queríamos trabajar, nosotras dijimos que sí, entonces ella dijo que nos iba a llevar a otro lugar donde era el trabajo y que iba a pagar mensual 70 soles. Nosotras les dijimos que queríamos estar solo 90 días para regresar a estudiar, ella nos dijo que no había ningún problema.

Entonces, hemos llegado para Itariato-Bajo, hemos llegado en un día entero en camión. Apenas llegamos a este lugar la señora cambió y empezó a maltratarnos. Pasaron los 90 días y no recibíamos ningún pago, queríamos irnos y la señora no nos dejaba, nos vigilaba y no nos daba dinero ${ }^{1}$.

Desde la teoría de la colonialidad se ha planteado magistralmente, hace muchos años atrás, una deriva de lo que en algún momento se definió en Latinoamérica como teoría de la dependencia. Un análisis histórico de la trata de personas obligaría a remontarse al comienzo de los tiempos, pero para el objeto de este escrito se analizará este fenómeno (como suceso procesual que puede ser leído en clave de las ciencias sociales) en el contexto de la modernidad y hasta la época actual.

De acuerdo con la teoría de la dependencia, y según se lo plantea en diversos estudios sobre la materia, se comprende, desde fines de la década de los sesenta, que los pueblos dependientes ingresan al mundo y con ello facilitan el desarrollo de los países centrales. Aquellos aportarán materias primas baratas, que estos últimos a su vez transformarán

1. Ivonne Macassi León, «Diagnóstico sobre trata de mujeres, niños y niñas en ocho ciudades del Perú» (Lima. Programa de Derechos Humanos de las Mujeres del CMP Flora Tristán, 2015), 65. 
en mercancías que más tarde serán consumidas por los primeros. Hoy, en un mundo neoliberal, ese esquema básico de reparto de misiones, funciones y poder de los países en el contexto internacional no ha variado demasiado. Los comienzos de esta lógica de integración a nivel planetario, denominada hace ya mucho tiempo como división internacional del trabajo, y en donde cada quien ocupa un lugar, hoy es definida como globalización y se inicia, según muchos pensadores, con el descubrimiento de América.

Quienes dieron origen a esta forma de concebir la distribución del poder señalan en sus estudios que ese comienzo fue no solo la distribución de misiones y funciones, sino al mismo tiempo el reparto inequitativo de poder, en donde su concentración máxima se ubicaba en Europa. Uno de los ejes estructurantes de las nuevas relaciones de poder, fue la clasificación jerárquica de la población mundial; en ella, ser europeo y blanco significaba ocupar el vértice superior de la pirámide, mientras que no serlo implicaba estar relegado a los estratos inferiores. Quienes se hallaban en la base de la pirámide tenían suerte si eran considerados seres humanos. En plena Conquista se desató una polémica acerca del carácter humano o sub humano de los conquistados, saldada al tiempo por Bartolomé de las Casas y otros religiosos en favor de los originarios.

Sin embargo, esa deuda saldada en los papeles y las bulas papales, estuvo lejos de trasladarse a la realidad cotidiana de los pueblos de América Latina y mucho menos a las poblaciones negras del África que ocupaban, en la escala jerárquica de seres humanos, el fondo de la pirámide o tal vez el mismo subsuelo. Por eso, eran literalmente cazados como animales para ser trasladados a América Central o más tarde al sur de EEUU y, allí, esclavizados. En ese esquema, a cada raza y su consecuente lugar en la escala de humanidad, y por ende, de poder, le correspondía una posición en relación con el trabajo diferente, a grandes rasgos se puede señalar que para los negros africanos estaba destinada la esclavitud, a los nativos de América la servidumbre bajo formas como la mita o el yanaconazgo y a los europeos la relación salarial, es decir, un estipendio en moneda por las tareas realizadas.

Si se pudiese volver la mirada hacia atrás y observar así la realidad de la población africana en el contexto de la Conquista, se verá que encaja perfectamente en la definición que hoy se consensua acerca del fenómeno de la trata de personas. Eran captados, literalmente cazados por europeos que viajaban y se instalaban en las costas del continente africano con ese objetivo; luego, los vendían en los puertos del Atlántico a otros sujetos que efectivizaban el traslado a tierras americanas; y una vez allí, eran nuevamente vendidos a quienes serían sus propietarios y los utilizarían especialmente en producciones agrarias bajo el régimen de la esclavitud. Solamente entre 1640 y 1870 salieron rumbo a América desde la costa entre el Rio Volta y Lagos-Onim, dos millones de esclavos ${ }^{2}$.

¿Por qué hoy las Naciones Unidas y los países que la integran dan a luz en el contexto de la Convención de Lucha contra el Crimen Organizado Trasnacional un protocolo especialmente destinado a la trata de personas? Muy simple, porque el fenómeno sigue existiendo. Según la Oficina de las Naciones Unidas contra la Droga y el Delito

2. Thomas Hugh, La trata de esclavos (Barcelona: Planeta, 1997), 357. 
(UNDOC), existen hoy 2,5 millones de personas afectadas. Es decir, aun en la actualidad, bajo formas novedosas, este fenómeno se encuentra presente. Un rastreo histórico puede servir para bucear en la vida de Theodore Canot, quien relata su experiencia como tratante de esclavos en un texto editado en Nueva York en 1857. Este personaje expone con espontaneidad y hasta con el cinismo propio de un aventurero, los acontecimientos de cazadores, mercaderes, piratas y todos los personajes que intervienen en la trata de esclavos africanos a principios del siglo XIX ${ }^{3}$. Para esa época habían pasado tres siglos de conquista y la realidad era la misma. Para el 2000, fecha de consagración del Protocolo de Palermo, habían transcurrido dos siglos más y se seguía en lo mismo.

Aquella marca de nacimiento a la cual hace referencia Quijano y en la cual se cruzan para la construcción de poder, raza y relación laboral, es el trasfondo de una historia que permanece intacta y que va mutando solo en la superficie con la lógica de rearticulación permanente de los factores constitutivos del capital. Los factores constitutivos del capital son la tríada capital, trabajo y Estado; y se articulan en un proceso denominado por István Mészáos como metabolismo social del capital. Este da cuenta de la fuerte interrelación sistémica que estructura las tres dimensiones que lo constituyen. La inexistencia de alguna de las tres dimensiones redundaría en una extinción de su lógica y no se puede pensar su superación sin la eliminación del conjunto de los elementos que comprende el sistema.

Entonces, como una primera hipótesis, se puede formular la siguiente proposición:

Las personas que ingresan al fenómeno de la trata de personas bajo la categoría de afectadas, se ubican en el cruce entre raza y trabajo, señalado por la teoría de la colonialidad.

Además, existen muchos testimonios que señalan un sendero de contrastación de esta hipótesis: "Yo nunca había visto una ciudad. En mi pueblo viven como doscientas o doscientas cincuenta personas. Nadie tiene luz ni agua. Tampoco hay escuela. La mayoría de la gente es analfabeta, como mis padres, y casi no hablan español» ${ }^{4}$. (Víctima de trata, originaria de Chiapas.) Si bien no existen estadísticas fiables, es de suponer que no todas las personas afectadas por el delito pertenecen a sectores sociales económicamente vulnerables.

En Chiapas, suroeste del territorio mexicano, viven 5218000 ciudadanos. En lo que respecta al nivel educativo, en el periodo 2013-2014, tuvo un grado promedio de escolaridad de 7\% por debajo del promedio nacional que es de $9 \%$, y un alto índice de analfabetismo $(15,5 \%)$ en comparación con el total nacional $(6 \%)$. Respecto de las características en cuanto a la raza, se puede señalar que es uno de los territorios en los que hay mayor densidad de pueblos originarios: «La CDI identifica 25 regiones indígenas en 20 estados del país, sin embargo, en todas las entidades federativas se encuentra población indígena. Al mismo tiempo, de los 2456 municipios existentes, 624 son indígenas y se concentran principalmente en los estados de Chiapas, Chihuahua, Guerrero, Hidalgo, Oaxaca, Puebla, San Luis Potosí, Veracruz y Yucatán» ${ }^{5}$.

3. Theodore Canot, Memorias de un tratante de esclavos (Buenos Aires: CEAL, 1976), 52-55.

4. Marta Torres Falcón, Con sus propias palabras: Relatos fragmentarios de víctimas de trata (México: CEAMEG-HCD, 2010), 39.

5. CDI, «Programa especial de los pueblos indígenas, 2014 -2018» (México, 2014), 14. 
Pero no es necesario trasladarse más de 7000 kilómetros para obtener información que aporte en la convalidación de la hipótesis planteada. En la Ciudad Autónoma de Buenos Aires se pueden encontrar talleres textiles atestados de ciudadanos de origen boliviano en situación de explotación, reducción a la servidumbre y víctimas de trata de personas. En informe de divulgación científica del Conicet-UBA, se lee: «Tráfico de personas, trata y reducción a la servidumbre son tres de los delitos asociados con la explotación de trabajadores inmigrantes de Bolivia en los talleres textiles clandestinos (TTC) de la ciudad de Buenos Aires y su área Metropolitana (AMBA), donde se fabrican prendas de indumentaria para diferentes marcas» ${ }^{6}$.

Como se observa, aun sin bucear profundamente en la realidad, la condición de raza y la sobre explotación del trabajo, bajo categorías delictuales como la esclavitud y la reducción a la servidumbre, están fuertemente anudadas en una maquinación férrea que destina cuerpos a la exclusión-extinción social en toda América Latina. Cabe destacar que para la teoría de la colonialidad, la condición de raza y la relación laboral no son sinónimo de pobreza o marginalidad, sino que definen una relación de poder. Ello explica que otras personas que no pertenecen a sectores sumidos en la pobreza y la marginalidad sean víctimas de trata.

\section{Segunda apostilla. Estado y capital}

Cada mes traían a nuevas personas, niños y niñas para trabajar. Los jefes son la dueña Fortunata Sequeiros y su marido. Su esposo que se llama Serapio, tienen un hijo menor que ayuda a vigilar y el mayor que es policía, y se encarga de traer jovencitos y mujeres indocumentadas de las batidas. Quise poner la denuncia en Radio Quillabamba pero cuando fui me dijeron que esa señora paga y que ella es bien conocida. Fui a poner la denuncia a la policía y no me han hecho caso, me han dicho que ella es bien conocida y que no puedo hacer nada?

Una segunda cuestión sobre la cual parece necesario hacer una breve reflexión, es sobre el Estado moderno en el contexto de la reproducción del capital, siendo que la evidencia empírica da cuenta del rol central de aquel, ya sea por acción o por omisión en el desarrollo del fenómeno de la trata de personas. Aquí, vale detenerse particularmente en el pensamiento de otro intelectual que ha marcado un hito en el pensamiento crítico finisecular. La referencia en este caso es el intelectual húngaro István Mèszáros. Y para este discípulo de Lukács, el Estado se erige como uno de los pilares constitutivos del capital. En este autor capital y capitalismo no son lo mismo; es más, este último es una de las formas que asume el capital históricamente. Su característica central es en realidad su metabolismo social de reproducción y los ejes que se articulan en dicho proceso son tres: capital, Estado y trabajo.

En Más allá del capital dice Mèszáros que el capitalismo es una de las formas posibles de realización del capital, una de sus variantes históricas, como ocurre en la fase caracterizada por la subsunción del trabajo al capital. Así como existía el capital antes de la

6. CONICET-UBA. «Talleres textiles clandestinos: fabricantes de enfermedades» (Buenos Aires, 2013 ), 1.

7. Ivonne Macassi León, Diagnóstico, 66. 
generalización del sistema productor de mercancías, del mismo modo se puede observar una presencia del capital después del capitalismo, a través de aquello que él denomina el sistema del capital poscapitalista.

Cuando Mèszáros hace referencia a formaciones poscapitalistas del capital, tiene en mente las experiencias ligadas al surgimiento y desarrollo de los llamados, en alguna época, socialismos reales ${ }^{8}$. Es decir, afirma que los procesos llevados adelante en la vieja y extinta Unión Soviética no fueron más que experiencias no capitalistas de reproducción del capital. Como es fácil de imaginar, ello le valió su exilio de la Hungría perteneciente al bloque soviético en el año 1956, con posterioridad a la invasión soviética.

Esta lectura crítica de la lógica del capital permitirá comprender la funcionalidad del Estado en su reproducción. De hecho, si alguno de aquellos ejes estuviese ausente, sencillamente no habría capital.

La línea de análisis desarrollada por este autor ayuda a ensayar un par de hipótesis que se señalan a continuación, la primera expresa que:

Frente a las visiones que afirman un retroceso de los Estados-nación en esta etapa de neoliberalismo planetario, con una globalización que anularía la soberanía sobre la cual se sustenta su misma esencia, se puede seguir pensando en clave de funcionalidad de los Estados respecto del capital.

Los Estados-nación no pueden desaparecer sino es a costa de la destrucción de los otros dos pilares que hacen a la reproducción sociometabólica del capital, es decir, capital y trabajo.

Y esta primera interrogante lleva a reflexionar sobre una segunda hipótesis. Esta se refiere a las características de la funcionalidad necesaria que religa Estado, capital y trabajo. En esa dirección se puede hipotetizar en el siguiente sentido:

Los Estados-nación ya no están en el centro de dicho proceso, pero siguen siendo funcionales al mismo aportando legitimidad desde la no intervención en la lógica del mercado y de la sobre intervención en clave de garantizar la disolución de aquellos conflictos que le ofrezcan resistencia.

A modo de ejemplo se podría recordar que en Argentina, a lo largo de la etapa más fuertemente neoliberal de los noventa, muchos autores señalaron de manera tajante la «ausencia» del Estado. Se hacía referencia a su retirada de aquellas responsabilidades que había asumido en plena vigencia de los procesos populistas. La educación, la salud de manera parcial y las políticas sociales de manera más general, vieron cómo las agencias gubernamentales daban las hurras y se retiraban a cuarteles de invierno según muchos de ellos. Luego de mucho tiempo se tomó conciencia de algo muy elemental que se había aprendido y luego olvidado de Max Weber, la omisión es una forma de acción social. Se descubrió más tarde que desfinanciar las políticas sociales y tercerizarlas a través de las organizaciones de la sociedad civil era una forma de estar presente, y que esa forma de

8. István Mèszáros, Más allá del capital (Bolivia, Vicepresidencia del Estado Plurinacional de Bolivia, 2010), 198-199. 
presencia era funcional a la reproducción del capital en esa etapa de su desarrollo, en ese específico lugar del planeta.

Ahora bien, llegado este punto, y con pleno conocimiento del rol que ejerce el Estado condicionando el surgimiento de la trata de personas, emerge la siguiente pregunta: ¿Cómo se produce y reproduce la trata de personas en un contexto de reconfiguración del Estado en etapa de capital neoliberal? Intentar avanzar hacia una respuesta, implica necesariamente reflexionar acerca de las diferencias que existirían entre un contexto en el cual el Estado es proclive a intervenir para regular el mercado y otro que deja librado a sus fuerzas la asignación de los recursos. En principio cabría destacar, a partir de un sinnúmero de testimonios, cómo los Estados están en la base de la construcción de la situación de vulnerabilidad a la cual hace referencia el protocolo de Palermo: «Hace varios años mis padres perdieron su terreno en Chiapas, por la ocupación de los militares. Mi padre no quiso migrar, pero tampoco encontró trabajo, porque no hablaba bien español. Yo empecé a trabajar de mesera en un restaurante. El dueño me dijo que podía viajar a la ciudad de México o a Estados Unidos para tener mejor empleo» (víctima de trata, originaria de Chiapas) ${ }^{9}$.

El fin último de la trata y las diferentes formas de explotación que son su objetivo final, constituyen formas de maximización del capital. De hecho la UNDOC señala que el mercado ilícito se estima en 32 billones de dólares.

La factibilidad de blanqueo del capital producto de las actividades ilegales del crimen organizado trasnacional, entre los cuales se encuentra la trata de personas, depende en parte de los controles que los Estados-nación lleven adelante sobre sus sistemas financieros. Estados con poca voluntad para regular los mercados de capitales serán más fácilmente escogidos a la hora de blanquear dinero procedente del crimen organizado, mientras que aquellos otros que establezcan mayores controles serán evitados para el desarrollo de esta fase del proceso, lo cual no significa que permanezcan fuera de todos los pasos que caracterizan a este delito. El Grupo de Acción Financiera Internacional (GAFI) ha elaborado una serie de recomendaciones para que los Estados ejerzan un control adecuado sobre sus sistemas financieros, con el fin de evitar este tipo de delitos; pero no todos los Estados se acogen a dichas directivas.

Frediani señala para el caso argentino, y tomando como año del señalamiento el 2002, que: «A todo ello se agrega la ausencia de mecanismos eficientes para el control de operaciones de lavado de dinero, que recién en el último año se inicia gradualmente su control, aunque aún no se ha terminado de constituir el ente encargado de ello y los mecanismos de control, procedimientos administrativos e informática para ello» ${ }^{10}$.

Otro ejemplo interesante que viene a cuento está referido a la trata con fines de explotación laboral en Argentina. En ese país hay una larga historia de protección y promoción de los derechos de los trabajadores que se traslada a mitad del siglo pasado. Entre 2003 y 2015, y luego de haber atravesado períodos de fuerte flexibilización del mercado

9. Torres Falcón, Con sus..., 40.

10. Ramón Frediani, «El sistema bancario argentino 1990-2001: Propuestas para su reconstrucción», Actualidad Económica año XII, n. ${ }^{\circ} 53$ (2002): 11-16. 
de trabajo, se han recuperado aquellos derechos. Esto permitió, por ejemplo, que la Procuración General de la Nación implementara un sistema de indicadores que orientan la intervención de los fiscales a la hora de discriminar entre situaciones de trata laboral o de simple trabajo informal y con ellos facilitar la tarea de la fiscalía en casos de trata laboral.

En un estudio sobre trata internacional con fines de explotación laboral en Argentina de niños y niñas de origen boliviano, se observa la responsabilidad del Estado por omisión:

Marcela viajó con sus propios documentos, pero no pasó por el puesto migratorio sino que cruzó la frontera caminando, sin que conste registro de su ingreso. Segunda nunca tuvo cédula de identidad -solo partida de nacimiento, que no sirve como documento de viaje-y cruzó la frontera con su hermano mayor sin que conozcamos datos del cruce. Ella y su hermano fueron detenidos en un control caminero en Reconquista (norte de la provincia de Santa Fe), donde se verificó la irregularidad de su ingreso y de su documentación. Hasta entonces, la joven, de 14 años, había cruzado la frontera internacional y atravesado por lo menos las provincias de Salta y $\mathrm{Chaco}^{11}$.

El Estado siempre es funcional a la reproducción del capital; es uno de los pilares de su reproducción sociometabólica y es importante tenerlo en cuenta a la hora de reflexionar sobre la trata de personas. Es de rigor observar tanto aquellos aspectos que legitiman la lógica del mercado como los dispositivos de intervención que buscan eliminar la resistencia que se estructure frente a esta.

\section{Tercera apostilla. Neoliberalismo genocida y extinción social}

Al llegar a Japón, y luego de haber cambiado su nombre por el de «Kelly», Marcela Loaiza ve que:

Me dijo que había pagado «mucho dinero» por mí, que ahora era de su propiedad y que si me portaba mal me vendería a la mafia yakuza. Me dijo: «Así es la vida. Le tocó a usted. A partir de ahora me debe cinco millones de yenes (doscientos millones de pesos colombianos) y deberá pagarme veinte mil yenes diarios. Es su deuda por los trámites de documentos, pasajes y su manutención. Le pagará a la mafia yakuza cada día diez mil yenes para poder trabajar. Tiene que ser bien puta. Siéntase orgullosa y deje el drama para luego. Ahora se llama Kelly.» Lloré. Intenté explicarle que todo era un error. Le dije que fui contratada como bailarina. Me siguió amenazando y le dije: «Hago lo que me pida, pero no toque a mi familia.» Me vestí con una minifalda, zapatos de tacón y plataforma y una blusa con escote. Me llevó a «putear» a la calle Ikebukuro en Tokio. Esa misma noche empezó mi pesadilla. Me dejó tirada en la calle y alcancé a gritarle: «¿Cómo me regreso?» Madame contestó: «Ya se lo dije: comiendo mierda y puteando» ${ }^{12}$.

El punto de partida en este tercer apartado es la consideración de la trata de personas (con todos sus fines de explotación) como un dispositivo más del "genocidio global"

11. Gloria Bonato, Estomba Laura y Pinto Gimol, La explotación sexual y laboral de la niñez y adolescencia en Argentina. 33 historias. Experiencias en la asistencia (Buenos Aires: Senaf-Unicef-OIM, 2013), 90.

12. Sanjuana Martínez, «Trata de blancas. Entrevista con Marcela Loaiza», Letras Libres (2010): 34-36. 
operado por el mercado en estadio de capital neoliberal. En un análisis más detallado de los procesos de trabajo que conducen a un escenario de exclusión-extinción social de grupos humanos a nivel planetario, se pueden observar las diferencias con las formas modernas de genocidio.

En esa dirección, y en un primer acercamiento, es justo destacar que los genocidios llevados adelante, a lo largo del siglo XX, han sido objeto de estudio central en las ciencias sociales. Para Daniel Feierstein, quien tal vez aportó más en la construcción de su conceptualización: «La peculiaridad del genocidio radica en que se propone la destrucción de un grupo, no solo de los individuos que lo conforman; su objetivo último radica en la destrucción de la identidad del grupo, logrando imponer la identidad del opresor» ${ }^{13}$.

Esta es una definición que fue retomada por el autor, de Raphael Lemkin, quien perdió a toda su familia en el holocausto nazi.

También se debe señalar que el siglo XX ha sido llamado el siglo del genocidio por el número de genocidios producidos y la cantidad de sus víctimas. La relación entre genocidio y Estado-nación ha sido afirmada por muchos autores. Existen aquellos que destacan el inherente potencial genocida del Estado moderno, como otros que reafirman dicha perspectiva al señalar que la cara antihumana del Estado moderno es el genocidio.

Los Estados-Nación en todos estos casos asumieron el rol central, diseñando y ejecutando planes sistemáticos orientados al exterminio de aquellos grupos humanos definidos como «no humanos». El primer paso fue negar la humanidad de quienes luego serían sometidos a aquellos procesos de trabajo dirigidos a la extinción social. Definirlos como sujetos en «estado de excepción» según lo señala Agamben, es el paso previo a procesarlos en una maquinaria mortífera ${ }^{14}$. Se produce una «secuestración identitaria» en la cual el sujeto queda fuera de la norma y el soberano puede disponer discrecionalmente de esa «nuda vida».

Dichos dispositivos de poder estatal dejaron como saldo millones de personas víctimas de genocidio a lo largo y ancho de todo el planeta.

Ahora bien, si el tráfico y la trata de personas existían de manera previa a la modernidad y continuó siendo una práctica usual a lo largo de aquella etapa histórica, su característica como proceso de trabajo no ha sido la propia de la lógica genocida moderna. Pero no estaría de más considerar que escapar de posibles genocidios fue en algunos casos el origen del fenómeno, es decir la captación y el traslado o la migración en condiciones de absoluta fragilidad. En el estudio histórico sobre la trata de personas en Argentina, Schnabel señala: "Las mujeres "importadas" a fines del siglo XIX y principios del XX provenían de Europa central y Rusia. A causa de la pobreza y la persecución religiosa que sufrían, sus padres las vendían a rufianes que fraguaban un matrimonio religioso entre la mujer explotada y explotador» ${ }^{15}$.

13. Daniel Feierstein, El genocidio como práctica social (Buenos Aires: FCE, 2016), 33.

14. Giorgio Agamben, Estado de excepción (Buenos Aires: Adriana Hidalgo Ed, 2004), 55.

15. Raúl Schnabel, Historia de la trata de personas en Argentina como persistencia de la esclavitud (La Plata: Ministerio de Justicia y Seguridad de la provincia de Buenos Aires, 2009), 9. 
El Estado moderno para estos casos actuaba como cómplice de su producción y reproducción, por acción u omisión. Schnabel señala, en el mismo estudio, que: «Como veremos, la trata de personas con fines sexuales siempre ha venido de la mano de la prostitución y ésta se ha tratado de un negocio ilegal, pero tolerado y hasta reglamentado por el Estado» ${ }^{16}$.

Se entiende entonces que los Estados modernos han ocupado un rol central, tanto en la generación de la oferta (persecución religiosa, pobreza, etc.) vía migración forzada, matrimonios forzados o pobreza, como de la demanda, a través de la legitimación de los fines de explotación para los cuales las personas eran tratadas o traficadas. En un testimonio recabado por Torres Falcón, se grafica la construcción de la oferta de cuerpos para ser explotados de la siguiente manera: "Yo nunca había visto una ciudad. En mi pueblo viven como doscientas o doscientas cincuenta personas. Nadie tiene luz ni agua. Tampoco hay escuela. La mayoría de la gente es analfabeta, como mis padres, y casi no hablan español» (víctima de trata, originaria de Chiapas) ${ }^{17}$.

La pregunta que surge entonces, es acerca de los cambios operados en los últimos 25 años de neoliberalismo pos caída del muro de Berlín y cómo el proceso definido como globalización ha impactado en dicha lógica. La centralidad del Estado parece haberse perdido en favor de la lógica del mercado y su legitimación por organismos trasnacionales como la Organización para la Cooperación y Desarrollo Económico (OCDE), el Fondo Monetario Internacional (FMI) y tratados de libre comercio como el Tratado de Libre Comercio de América del Norte (TLCAN) o el Acuerdo Transpacífico de Cooperación Económica. Una nueva institucionalidad trasfronteriza impacta de lleno en las lógicas locales y a su vez, estas últimas son la garantía de efectiva reproducción del orden global. Se lo ha señalado aquí y también fue planteado en diversos estudios sociológicos sobre la globalización y la reproducción en el orden local a través de las ciudades globales.

Lo que está en juego, o por lo menos entre signos de interrogación, es la soberanía de los Estados-nación. Negri y Hardt señalan que: «Antes de investigar la constitución del imperio en términos jurídicos, debemos analizar con cierto detalle el proceso constitucional que ha venido a definir las categorías jurídicas centrales, y en particular prestar mucha atención al proceso de la prolongada transición desde el derecho soberano de los Estados-nación (y el derecho internacional que provino de allí) hasta las primeras figuras globales posmodernas del derecho imperial» ${ }^{18}$.

Si bien, esta mirada puede ser relativizada (al menos por ahora los Estados-nación no parecen estar en estado de extinción), no es menos verídico que el peso de los organismos financieros internacionales y de comercio ha sido determinante en la crítica trayectoria del mercado global y sus consecuencias en las economías nacionales.

La consecuencia más significativa de estos cambios operados en el orden global, es la centralidad que ha ganado el mercado y sus actores en la definición de las reglas de juego y el rol de legitimador de estas que llevan adelante los Estados-nación, respondiendo al

16. Raúl Schnabel, Historia de la ..., 12.

17. Marta Torres Falcón, Con sus..., 36.

18. Michael Hardt y Toni Negri, Imperio (Buenos Aires: Paidós, 2002), 34. 
ya señalado en otra parte de este estudio, metabolismo social del capital. Dicho más explícitamente, el Estado opera otorgando legitimidad a las reglas que impone el mercado global y abandona a su suerte a los sectores que menos poder tienen para hacer valer su posición en el mismo. Es en este contexto en el cual se hace necesario repensar el genocidio como un dispositivo de poder de noveles formas y por ello como una práctica de gubernamentalidad orientada a la exclusión-extinción social. En donde:

La dinámica social de la extinción no es solo un proceso citado metafóricamente, posee cuatro vertientes empíricas que pueden verificarse en la práctica social del sistema: a. la extinción del ser sociocultural precedente para fracciones crecientes de la clase trabajadora y de las etnias locales; b. la contradicción máxima del sistema para autodestruirse y pasar de un capitalismo legitimable a una formación económica predominantemente coactiva; c. la producción de población extinta o con muy baja capacidad de sobrevivencia a través de los procesos de indigencia, migración clandestina, criminalización, la emergencia de nuevas y viejas formas de patologización (sida, drogadicción, desnutrición, tuberculosis, locura y otras) y finalmente; d. la fragmentación del espacio social urbano con intensos procesos de guetificación ${ }^{19}$.

Las reglas del juego han cambiado y con ello también aparece un nuevo escenario. Brodsky señala, citando a Pramono, que: «el neoliberalismo es genocida porque va expresamente dirigido a atacar las bases culturales de existencia del proletariado industrial; de hecho, el neoliberalismo genera desocupación estructural prolongada en el tiempo, lo que a la larga provocará la destrucción de determinado tipo de relaciones sociales y la aparición y consolidación de otras» ${ }^{20}$.

Más allá de lo acertado de la afirmación anterior, se debe destacar que el capital en etapa neoliberal es mucho más que su garantía de reproducción material. Sus aspectos cultural y simbólico son centrales a la hora de modelar subjetividades apropiadas a este desarrollo histórico. Ya lo había advertido Marcusse mucho antes de los postulados del consenso de Washington, promediando la década de los sesenta: "Así surge el modelo de pensamiento y conducta unidimensional en el que ideas, aspiraciones y objetivos, que trascienden por su contenido el universo establecido del discurso y la acción, son rechazados o reducidos a los términos de este universo» ${ }^{21}$.

En el capital en etapa neoliberal no solo ha mutado la forma de acumulación ampliada y de reproducción material, sino que ello tuvo su correlato en la producción de nuevas subjetividades, sean estas para la vida o para la muerte.

En la misma dirección se expresa Alemán al decir «que el orden simbólico que atraviesa al neoliberalismo, se comporta como un dispositivo racional que aparenta promover diversas formas de subjetividad, mientras la repetición de lo mismo en el circuito ilimitado de la mercancía prosigue su marcha incesante y circular» ${ }^{22}$.

19. Alberto Bialakowsky, et al, Procesos sociales de exclusión-extinción. Comprender y coproducir en las prácticas institucionales en Núcleos Urbanos Segregados (México: UAEM-CEMAPEM-ALAS, 2004), 115.

20. Patricio Brodsky, El neoliberalismo como forma particular de genocidio (Buenos Aires: Página Popular, 2016).

21. Herbert Marcusse, El hombre unidimensional (Barcelona: Ariel, 1968), 42.

22. Jorge Alemán, Horizontes neoliberales en la subjetividad (Buenos Aires: Grama, 2016), 13. 
Si los genocidios de la modernidad han sido definidos como una tecnología de poder que apunta a la «reorganización» de la sociedad, la etapa de capital en estadio neoliberal y su consecuente cuestionamiento de la soberanía estatal, obliga a una necesaria redefinición. Si el campo de concentración y sus procesos de trabajo tenían como horizonte la desaparición y exterminio del otro considerado negativamente y fueron los instrumentos del Estado moderno para llevar adelante una reconfiguración del orden social, ¿cuáles serán hoy los dispositivos que bajo la lógica del mercado logren dicho objetivo?

La hipótesis que se puede afirmar en este tercer apartado es que:

La trata de personas como fenómeno social, constituye un dispositivo de poder orientado a la exclusión-extinción social en el contexto del capital en etapa neoliberal.

No es el único dispositivo de poder, sino que forma parte de un conjunto de ellos y todos operan favorecidos por la fragmentación y dispersión del mercado en la etapa actual de reproducción del capital. «Fátima Mansilla tenía 16 años cuando fue secuestrada por Alejandro González y Daniela Milhein. Despertó en un prostíbulo de Tucumán en donde se encontró con Marita. No estaba bien. Hablaba tartamudeando. Parecía drogada, tenía los ojos bien rojos, hinchados los párpados y grandes ojeras moradas» ${ }^{23}$.

María de los Ángeles Verón fue secuestrada en la provincia de Tucumán, Argentina, el 3 de abril de 2002; nunca más apareció, está desaparecida.

\section{Conclusiones}

A modo de síntesis final se puede destacar la importancia de alejarse un momento de los acontecimientos para echar una mirada al contexto de producción de la trata de personas como un fenómeno social que responde a una realidad contextual específica. Se destacaron en esa dirección tres elementos que pueden ayudar a una mejor comprensión de este.

En primer lugar, se rescata los aportes de la teoría de la colonialidad y desde allí se puede observar un contexto en donde raza y género se cruzan para dar vida a formas de dominación que garantizan la captación en grupos humanos en situación de vulnerabilidad.

En segundo lugar, se avanza en un breve análisis de la lógica del capital en el actual estadio neoliberal. Aquí se busca dar cuenta de la novedad de estadio, en clave de la centralidad que sume el mercado y la complementariedad del Estado y las políticas públicas. En este sentido y a modo de ejemplo, la financiarización de la economía y la liberalización de los mercados favorece el lavado de dinero obtenido por el crimen organizado.

Finalmente, la segunda apostilla conduce a la tercera reflexión. El contexto de producción de la trata de personas es aquel en el cual las estrategias de gubernamentali$d a d$, son definidas en el mercado y luego ejecutadas de manera complementaria por las

23. Eldiario24.com, Las víctimas que vieron a Marita Verón contaron escalofriantes relatos (Tucumán, Eldiario24.com, 2002). 
políticas públicas. La direccionalidad de estas es la tanatopolítica y con ello la exclusiónextinción social de seres humanos pertenecientes a grupos en situación de vulnerabilidad.

Quedan interrogantes por resolver. Un buen acicate para seguir investigando y construyendo saber colectivo.

\section{ABSTRACT}

Violence, human trafficking and social extinction: Apostilles over its context and socio historical transformation

Human trafficking has taken several forms along history. The purpose of this paper is to try to understand the current scenario (Capital in neoliberal stage), pointing out the changes that have taken place. The paper includes a journey over three apostilles in the form of an essay over the matter at hand. The first path includes the questioning proposed by the colonial theory in the reproduction of power patterns. The second path puts in place a short description of the neoliberal stage of capitalism. To conclude, there is an analysis of the journey of societies whose government mechanisms generate exclusion and social extinction as a mean of human trafficking.

Key words: human trafficking, coloniality, capital of the neoliberal stage, State, neoliberal genocide, exclusion-social extinction.

\section{RÉSUMÉ}

Violence, traite des êtres humains et extinction sociale : Annotations sur son contexte et son évolution sociale historique

La traite des êtres humains a pris de diverses formes au cours de l'histoire. Il s'agit de comprendre le scénario actuel (Capital en stade néolibéral) en signalant les changements qui se sont donnés dans ce stade par rapport le précédant. Cet essai propose un parcours à travers de trois parties sur le problème en question. La première partie développe les questionnements postulés par la théorie de la colonialité concernant la reproduction des modèles de pouvoir. La deuxième vise à décrire brièvement le rôle de l'État-Nation dans le stade néolibéral du Capital. Et pour conclure, la troisième partie analyse le passage vers sociétés dont les dispositifs de gouvernementalité produisent exclusion-extinction sociale, en comprenant la traite des êtres humains comme l'un de ces dispositifs.

Mots-clés: traite des êtres humains, colonialité, capital en stade libéral, État, génocide néolibéral, exclusion-extinction sociale.

\section{Bibliografía}

Agamben, Giorgio. Estado de excepción. Buenos Aires: Adriana Hidalgo Editora, 2004.

Alemán, Jorge. Horizontes neoliberales en la subjetividad. Buenos Aires: Grama, 2016.

Bialakowsky, Alberto, Crudi, Roxana, Costa, María Ignacia, Haimovici, Nora, Reynals, Cristina y Zagami, Mónica. «Procesos sociales de exclusión-extinción. Comprender y coproducir en las prácticas institucionales en Núcleos Urbanos Segregados». En: Desigualdad, pobreza, exclusión y vulnerabilidad en América Latina. Nuevas perspectivas en América Latina. Dirigido por Laura Mota Díaz y Antonio David Cattani. México. Ed: UAEM-CEMAPEM-UFRGS-ALAS, 2004. 
Bonato, Gloria, Laura Estomba y Gimol Pinto. La explotación sexual y laboral de la niñez y adolescencia en Argentina. 33 historias. Experiencias en la asistencia. Buenos Aires: Senaf-Unicef-OIM, 2013.

Brodsky, Patricio. «El neoliberalismo como forma particular de genocidio», Página Popular, 11 de octubre, 2016. Acceso: 28 de abril, 2017, http://www.paginapopular.net/neoliberalismo-como-genocidio/

Canot, Theodore. Memorias de un tratante de esclavos. Buenos Aires: CEAL, 1976.

CDI. Programa especial de los pueblos indígenas, 2014-2018, 2014. Acceso: 28 de abril, 2017, https://www.gob. $\mathrm{mx} / \mathrm{cms} /$ uploads/attachment/file/32305/cdi-programa-especial-pueblos-indigenas-2014-2018.pdf

CONICET-UBA. Talleres textiles clandestinos: fabricantes de enfermedades. 11 de abril, 2013. Acceso: 28 de abril, 2017, http://www.conicet.gov.ar/talleres-textiles-clandestinos-fabricantes-de-enfermedades/

Eldiario24.com. Las víctimas que vieron a Marita Verón contaron escalofriantes relatos. Acceso: 28 de abril, 2017, http://www.eldiario24.com/nota/245860/relatos-las-mujeres-que-fueron-secuestradas-dieron-testimonio-de-haber-visto-a-la-joven-secuestrada-en-2002-fotos-infobae.html

Feierstein, Daniel. El genocidio como práctica social. Buenos Aires: Fondo de Cultura Económica, 2016.

Frediani, Ramón. El sistema bancario argentino 1990-2001: Propuestas para su reconstrucción. Buenos Aires: Actualidad Económica, Año XII, n. ${ }^{\circ}$ 53, 2002.

Hardt, Michael y Negri, Toni. Imperio. Buenos Aires: Paidós, 2002.

Hugh, Thomas. La trata de esclavos. Barcelona: Planeta, 1997.

Macassi León. Ivonne. Diagnóstico sobre trata de mujeres, niños y niñas en ocho ciudades del Perú. Lima: Programa de Derechos Humanos de las Mujeres del CMP Flora Tristán, 2015.

Marcusse, Herbert. El hombre unidimensional. Barcelona. Ariel. 1968.

Martínez, Sanjuana. «Trata de blancas. Entrevista con Marcela Loaiza». Letras Libres, 30 de abril, 2010. Acceso: 28 de abril, 2017, http://www.letraslibres.com/mexico/trata-blancas-entrevista-marcela-loaiza

Mèszáros, István. Más allá del Capital. Bolivia: Vicepresidencia del Estado Plurinacional de Bolivia, 2010.

Schnabel. Raul. Historia de la trata de personas en Argentina como persistencia de la esclavitud. La Plata: Ministerio de Justicia y Seguridad de la Provincia de Buenos Aires, 2009.

Torres Falcón. Marta. Con sus propias palabras: Relatos fragmentarios de víctimas de trata. México: CEAMEGHCD, 2010 . 